\title{
Perbandingan Metode Ekstraksi Ciri Histogram dan PCA untuk Mendeteksi Stoma pada Citra Penampang Daun Freycinetia
}

\section{Comparison of Histogram and PCA as Feature Extraction Methods in Detecting Stoma in Freycinetia Leaf Images}

\author{
DONY SATRIA, MUSHTHOFA *
}

\begin{abstract}
Abstrak
Ekstraksi fitur adalah proses pengambilan ciri sebuah objek yang dapat menggambarkan karakteristik dari objek tersebut. Pada penelitian ini, dua buah metode ekstraksi fitur digunakan, yaitu Principal Component Analysis (PCA) dan histogram untuk melakukan deteksi stoma pada gambar penampang daun Freycinetia. Penelitian ini menggunakan frame berjalan yang melakukan pengolahan bagian citra dan melakukan deteksi kemunculan stoma pada bagian citra tersebut. Untuk memodelkan kemunculan stoma, dibuat tiga kelas frame, yaitu frame dengan kemunculan stoma penuh, frame dengan kemunculan sebagian stoma, dan frame tanpa kemunculan stoma. Untuk proses klasifikasi, digunakan pemodelan menggunakan Jaringan Saraf Tiruan (JST) Backprogragation. Hasil percobaan menunjukkan bahwa ekstraksi fitur menggunakan PCA menghasilkan akurasi yang lebih baik dibandingkan dengan metode histogram. Nilai F1-measure yang terbaik yang didapatkan menggunakan ekstraksi fitur PCA ialah 0.9091.
\end{abstract}

Kata kunci: deteksi stoma, ekstraksi fitur, Freycinetia, histogram, PCA

\begin{abstract}
Feature extraction is the process of taking an object identifier which can describe the characteristics of the object. In this study, we use two feature extraction methods, namely Histogram and PCA (Principal Component Analysis) to be used in stoma detection from the Freycinetia sectional leaves images. We used a moving frame to detect the occurrence of stoma in an image. To create a classification model, we distinguish between three frame classes: frames showing full stoma, frames showing parts of stoma, and frames which contain no part of stoma at all. For the classification method, we use the Backpropagation Artificial Neural Network for the classifier. The results of the detection process using Histogram as the feature extraction method will be compared with the results of the detection process using PCA. The best results between the two methods of feature extraction will be used as the first step in the process of species type identification for the genus Freycinetia. The research results show that the PCA feature extraction method is better than the Histogram feature extraction method in detecting the occurrence of stoma on the Freycinetia sectional leaves images. The best f1-measure value that can be achieved by the PCA feature extraction methods is 0.9091 .
\end{abstract}

Keywords: feature extraction, Freycinetia, histogram, leaf image, PCA, stoma detection

\section{PENDAHULUAN}

Freycinetia adalah genus terbesar kedua dari famili Pandanaceae yang memiliki jenis spesies yang sangat beragam. Saat ini, diperkirakan terdapat 200-300 jenis spesies Freycinetia di seluruh dunia. Spesies-spesies yang termasuk ke dalam genus tersebut memiliki ciri morfologi yang hampir serupa. Karena kesamaan ciri morfologi tersebut, spesies yang satu dengan spesies yang lainnya sangat sulit dibedakan sehingga, ketika ditemukan tumbuhan yang termasuk ke dalam genus Freycinetia, jenis spesies dari tumbuhan tersebut sulit untuk dikenali. Pengenalan dan klasifikasi terhadap jenis spesies Freycinetia perlu dilakukan untuk mengetahui nilai potensial dan kegunaan, serta penyebaran koleksi plasma nutfah Freycinetia pada keanekaragaman sumber daya hayati (Qur'ania 2012). 
Parameter paling tepat yang dapat digunakan untuk melakukan pengenalan jenis spesies Freycinetia ialah ciri anatomi stoma (Willmer 1983). Karakter anatomi stoma yang dapat diamati ialah bentuk, kerapatan, panjang, lebar, luas, jumlah sel penjaga, ukuran sel epidermis, dan indeks stoma (perbandingan antara jumlah stoma dan jumlah sel epidermis pada luas area tertentu).

Penelitian mengenai pengenalan jenis/varian dari spesies tumbuhan menggunakan ciri morfologi stoma berbasis citra telah dilakukan sebelumnya. Sanyal et al. (2008) menggunakan citra scanning electron microscopy (SEM) dalam menganalisis fitur morfologis dari stoma daun beberapa spesies tomat untuk mengenali varietasnya. Penelitian menggunakan ciri anatomi stoma pada jenis spesies Freycinetia telah dilakukan oleh Pasaribu (2010). Pada penelitian tersebut, rata-rata ukuran stoma, frekuensi stoma, dan indeks stoma masing-masing spesies dihitung secara manual. Perhitungan tersebut memberikan hasil yang berbeda di antara 14 spesies yang digunakan.

Qur'ania (2012) melakukan proses klasifikasi terhadap empat spesies Freycinetia menggunakan citra digital anatomi stoma. Proses klasifikasi tersebut menggunakan analisis ekstraksi ciri terhadap komponen nilai RGB dan nilai grayscale, serta ekstraksi ciri terhadap nilai dekomposisi Wavelet. Akurasi klasifikasi terbaiknya ialah sekitar 90\%. Penelitian tersebut merupakan suatu cara untuk melakukan pengenalan spesies Freycinetia secara otomatis, namun data yang digunakan pada penelitian tersebut adalah citra anatomi stoma secara keseluruhan (citra penampang paradermal daun) yang di dalamnya terdapat sel-sel epidermis dan stoma sehingga terdapat kemungkinan bahwa apabila data yang digunakan adalah stoma yang dipisahkan dari sel-sel epidermis, akurasi klasifikasi yang dihasilkan dapat ditingkatkan.

Pemisahan antara stoma dan sel-sel epidermis yang mengelilinginya diharapkan mampu mendeteksi letak atau posisi kemunculan stoma pada citra penampang daun Freycinetia sehingga, pada penelitian selanjutnya, dari stoma yang terdeteksi tersebut berbagai analisis seperti penghitungan rata-rata ukuran stoma, frekuensi stoma, kerapatan stoma, jarak antarstoma, dan indeks stoma dapat dihitung untuk menemukankan penciri atau karakteristik dari setiap spesies Freycinetia.

Tujuan utama penelitian ini ialah membandingkan metode ekstraksi ciri PCA dan histogram dalam melakukan pendeteksian stoma pada sebuah gambar penampang daun Freycinetia. Metode ekstraksi fitur yang terbaik dapat digunakan pada penelitian selanjutnya untuk pengenalan daun Freycinetia.

\section{METODE}

Garis besar metode penelitian ini terdiri atas beberapa langkah alur kerja yang dijelaskan pada Gambar 1.

\section{Pengumpulan Data}

Data citra penampang daun Freycinetia yang digunakan dalam penelitian ini diperoleh dari Pasaribu (2010). Data tersebut terdiri atas tiga jenis spesies, yaitu: Freycinetia angustifolia, $F$. imbricata, dan $F$. javanica. Setiap spesies terdiri atas 24 citra penampang daun. Setiap citra penampang daun memiliki dimensi 480 x 640 piksel dengan model warna RGB dan memiliki format penyimpanan JPEG. 


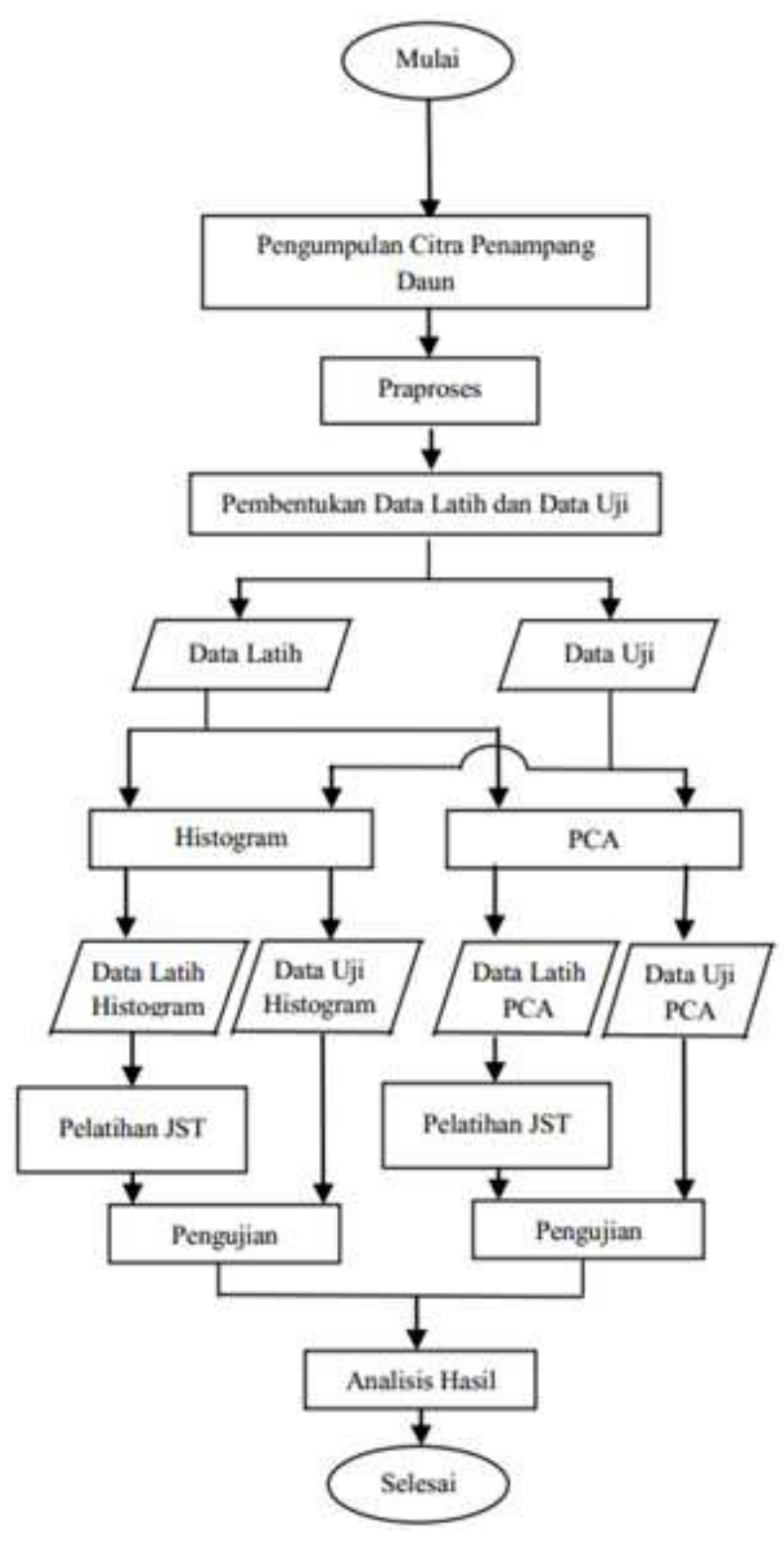

Gambar 1 Alur kerja penelitian

\section{Praproses Data}

Tahapan ini terdiri atas dua bagian, yaitu:

\section{Konversi RGB menjadi Grayscale}

Setelah seluruh data citra penampang daun terkumpul, citra-citra tersebut kemudian diubah ke dalam model grayscale. Konversi model citra dari RGB menjadi grayscale dilakukan dengan pengubahan komposisi dengan menggunakan Persamaan 1,

$$
\text { Grayscale }=\alpha R+\beta G+\delta B
$$

dengan nilai $\alpha=0.299, \beta=0.587$ dan $\delta=0.11$ (Gonzalez dan Woods 2008).

\section{Windowing}

Setelah diubah ke dalam model grayscale, langkah selanjutnya adalah proses windowing, yaitu pemotongan citra penampang daun dengan ukuran window tertentu secara overlapping. Window yang digunakan pada penelitian ini memiliki dimensi 90x70 piksel, dengan jarak overlapping yang digunakan adalah 30 piksel. Ukuran window ini telah disesuaikan dengan 
dimensi dari seluruh stoma yang muncul di setiap citra penampang daun. Proses windowing tersebut dapat dilihat pada Gambar 2.

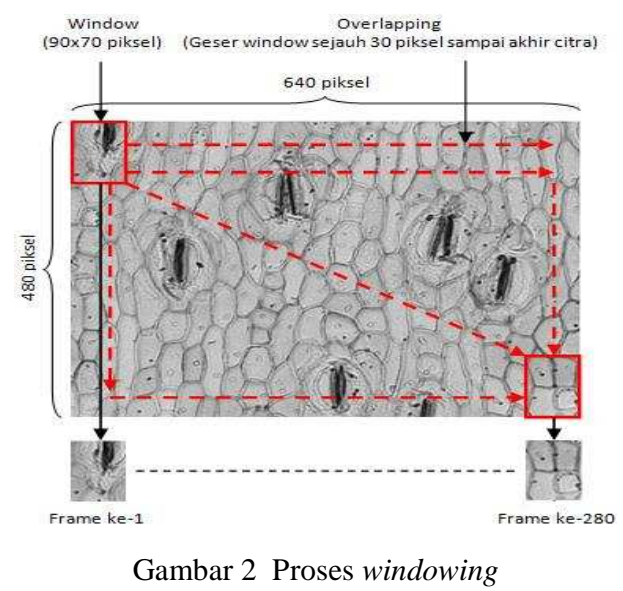

Dari seluruh frame yang dihasilkan pada proses windowing, terbentuk tiga jenis frame dengan karakter yang berbeda. Jenis pertama adalah frame yang di dalamnya terlihat stoma secara utuh (frame stoma). Jenis kedua adalah frame yang di dalamnya terlihat stoma, namun hanya sebagian (frame sebagian stoma), dan jenis ketiga adalah frame yang di dalamnya tidak terlihat stoma sama sekali (frame bukan stoma). Contoh dari ketiga jenis frame tersebut dapat dilihat pada Gambar 3.

\section{Pembentukan Data Latih dan Data Uji}

\section{Pemilihan Citra Penampang Daun Latih dan Citra Penampang Daun Uji}

Frame yang digunakan sebagai data latih dan data uji berasal dari citra penampang daun yang berbeda. Hal ini karena pada proses pengujian, input yang digunakan adalah sebuah citra penampang daun secara utuh sehingga seluruh frame yang dihasilkan dari suatu citra penampang daun uji akan digunakan sebagai data uji dan tidak bisa digunakan sebagai data latih. Hal tersebut dilakukan agar dari proses pengujian dapat dilihat hasil deteksi kemunculan stoma terhadap sebuah citra penampang daun uji.

\section{Pemilihan Frame dari Citra Penampang Daun Latih dan Citra Penampang Daun Uji}

Untuk citra penampang daun latih, tidak semua frame yang terbentuk akan digunakan sebagai data latih. Hal ini karena jumlah frame yang dihasilkan terlalu banyak sehingga hanya akan dipilih beberapa frame saja. Frame yang dipilih tersebut harus bervariasi sehingga dapat mewakili frame-frame lainnya yang tidak terpilih. Dari tiap-tiap spesies, frame stoma yang terbentuk akan digunakan seluruhnya. Adapun frame sebagian stoma yang terbentuk hanya akan digunakan 100 frame dan frame bukan stoma yang terbentuk hanya akan digunakan 150

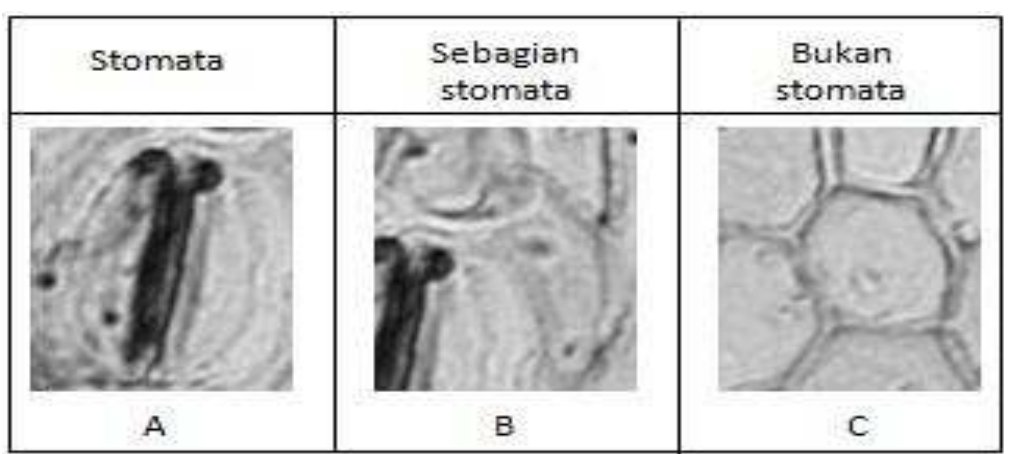

Gambar $3 \mathrm{~A}=$ frame stoma, $\mathrm{B}=$ frame sebagian stoma, dan $\mathrm{C}=$ frame bukan stoma 
frame.

Untuk citra penampang daun uji, seluruh frame yang terbentuk akan digunakan sebagai data uji. Hal ini karena pada proses pengujian, data uji yang digunakan adalah berupa citra penampang daun secara utuh dan hasil dari proses pengujian tersebut akan dikembalikan ke citra asal sehingga dapat dilihat daerah-daerah pada citra tersebut yang terdeteksi sebagai frame stoma, frame sebagian stoma, dan frame bukan stoma.

\section{Transformasi Frame dari 2D menjadi 1D}

Sebelum memasuki tahap ekstraksi ciri, setiap frame yang digunakan sebagai data latih dan data uji harus ditransformasi ke dalam bentuk vektor (frame dengan bentuk 1 dimensi). Karena setiap frame memiliki dimensi $90 \times 70$ piksel, setelah melalui proses transformasi, dimensi dari frame tersebut berubah menjadi $1 \times(90 \times 70)$ atau $1 \times(6300)$ piksel.

\section{Ekstraksi Ciri}

\section{Histogram}

Histogram menunjukkan distribusi piksel berdasarkan intensitas graylevel (derajat keabuan) yang dimiliki oleh tiap-tiap piksel. Penggunaan histogram sebagai metode ekstraksi ciri didasarkan pada perbedaan sebaran atau distribusi piksel yang terjadi di antara frame stoma, frame sebagian stoma, dan frame bukan stoma. Pada metode ekstraksi ciri histogram, bin merupakan banyaknya batang warna yang akan terbentuk, atau menunjukkan jumlah pembagian rentang warna pada histogram. Jumlah titik ekstraksi ciri yang dihasilkan oleh suatu histogram adalah sama dengan jumlah bin yang digunakan pada histogram tersebut. Pada penelitian ini, nilai bin yang dicoba adalah 10, 20, 30, 40, dan 50 bin.

\section{PCA (Principal Component Analysis)}

Tujuan dari metode ekstraksi ciri PCA adalah memproyeksikan data latih dari suatu ruang dimensi tertentu ke ruang dimensi yang lebih rendah, tanpa kehilangan banyak informasi yang terkandung (Jolliffe 2002). Metode ekstraksi ciri PCA akan memberikan dua keluaran utama, yaitu matriks penciri dari data latih dan matriks transformasi. Matriks transformasi nantinya akan digunakan untuk mentransformasi data uji agar berada pada ruang dimensi yang sama dengan ruang dimensi dari data latih.

Dengan metode ekstraksi ciri PCA, nilai persentase data yang ingin dibuang, atau data yang dianggap kurang penting, dapat ditentukan. Pada penelitian ini, nilai persentase pembuangan komponen utama yang digunakan adalah $0.04 \%, 0.05 \%, 0.06 \%, 0.07 \%, 0.08 \%$, $0.09 \%$, dan $0.10 \%$. Semakin besar persentase komponen utama yang dibuang, perhitungan selanjutnya semakin efisien. Namun, hal ini dapat berakibat pada berkurangnya akurasi.

\section{Pelatihan Jaringan Saraf Tiruan (JST)}

Algoritme yang digunakan dalam tahap pelatihan JST adalah backpropagation. Fungsi transfer yang digunakan pada lapisan tersembunyi adalah logaritmik sigmoid, fungsi transfer yang digunakan pada lapisan output adalah logaritmik sigmoid, dan fungsi training jaringan adalah fungsi Levenberg-Marquardt. Untuk jumlah neuron pada lapisan tersembunyi, akan

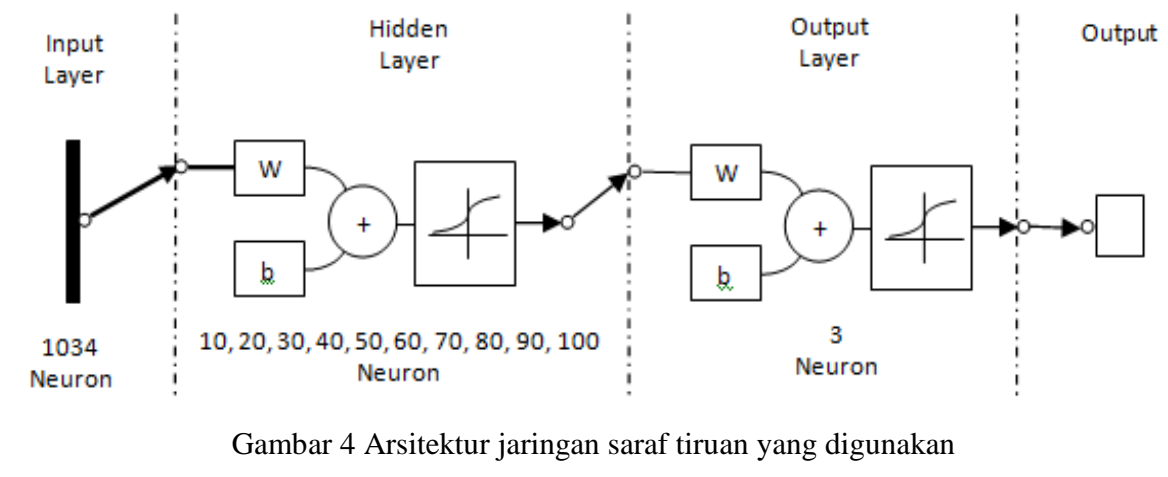


dicoba sepuluh nilai yang berbeda, yaitu 10, 20, 30, 40, 50, 60, 70, 80, 90, dan 100 neuron. Arsitektur dari JST yang digunakan pada penelitian ini dapat dilihat pada Gambar 4.

\section{Pengujian}

Tahap pengujian ini dilakukan beberapa kali sesuai dengan jumlah citra penampang daun uji. Input dari setiap proses pengujian adalah sebuah citra penampang daun uji yang telah melewati tahap praproses dan ekstraksi ciri, serta matriks target dan sebuah jaringan terbaik yang dihasilkan pada proses pelatihan JST. Hasil dari proses pengenalan atau pengujian ini, akan dikembalikan ke citra penampang daun yang bersangkutan untuk melihat daerah-daerah pada citra tersebut yang terdeteksi sebagai kelas pertama (frame stoma), kelas kedua (frame sebagian stoma), dan kelas ketiga (frame bukan stoma).

\section{Analisis Hasil}

Langkah pertama dalam tahap analisis adalah menghitung nilai recall, precison, dan $f_{1 \_}$measure. Penghitungan nilai recall dan precision membutuhkan suatu matriks yang disebut dengan confusion matrix. Matriks tersebut dapat dilihat pada Tabel 1 (Manning et al. 2008). Definisi recall ditunjukkan pada Persamaan 2, sedangkan definisi precision ditunjukkan pada Persamaan 3.

Tabel 1 Confusion matrix

\begin{tabular}{lcc}
\hline & Stoma & Bukan Stoma \\
\hline $\begin{array}{l}\text { Terdeteksi Sebagai } \\
\text { Stoma }\end{array}$ & tp & Fp \\
$\begin{array}{l}\text { Terdeteksi Sebagai } \\
\text { Bukan Stoma }\end{array}$ & fn & th \\
\hline
\end{tabular}

Keterangan:

tp: true positive (jumlah stoma pada citra penampang daun yang berhasil terdeteksi sebagai stoma).

tn: true negative (jumlah bukan stoma pada citra penampang daun yang berhasil terdeteksi sebagai bukan stoma).

fp: false positive (jumlah bukan stoma pada citra penampang daun yang terdeteksi sebagai stoma).

fn: false negative (jumlah stoma pada citra penampang daun yang terdeteksi sebagai bukan stoma).

$$
\begin{gathered}
\text { recall }=\frac{t p}{t p+f n} \\
\text { precision }=\frac{t p}{t p+f p}
\end{gathered}
$$

F_measure (Manning et al. 2008) adalah ukuran kinerja klasifikasi dalam mendeteksi kemunculan stoma dengan mengombinasikan nilai recall dan nilai precision. Persamaan dari f_measure ditunjukkan pada Persamaan 4.

$$
f_{\beta-\text { measure }}=\left(1+\beta^{2}\right) \cdot \frac{\text { precision } \cdot \text { recall }}{\beta^{2} \text { precision }+ \text { recall }}
$$

Pada penelitian ini, nilai $\beta$ yang digunakan adalah 1 sehingga persamaan $f$ measure di atas berubah sebagaimana ditunjukkan pada Persamaan 5 .

$$
f_{1} \text { measure }=2 \cdot \frac{\text { precision } \cdot \text { recall }}{\text { precision }+ \text { recall }}
$$

Nilai 1 tersebut menyatakan bahwa bobot yang diberikan untuk recall dan precision adalah sama. 


\section{HASIL DAN PEMBAHASAN}

\section{Pengujian}

Input dari proses pengujian adalah sebuah citra penampang daun uji beserta jaringan terbaik yang diperoleh pada tahap pelatihan JST. Hasil dari proses pengujian ini akan dikembalikan ke citra penampang daun uji yang bersangkutan untuk melihat daerah-daerah pada citra penampang daun uji tersebut yang terdeteksi sebagai kelas pertama (frame stoma), kelas kedua (frame sebagian stoma), dan kelas ketiga (frame bukan stoma). Contoh hasil dari proses pengujian dapat dilihat pada Gambar 5 .

Gambar 5 memperlihatkan kotak-kotak berwarna putih dan hitam. Kotak putih menunjukkan bahwa daerah tersebut merupakan daerah yang terdeteksi sebagai frame stoma. Kotak hitam menunjukkan bahwa daerah tersebut merupakan daerah yang terdeteksi sebagai frame sebagian stoma. Selain kotak putih dan kotak hitam, terdapat juga daerah tanpa kotak yang merupakan daerah yang terdeteksi sebagai frame bukan stoma.

Pada Gambar 5, terlihat beberapa stoma yang seharusnya terdeteksi sebagai sebuah stoma, namun muncul beberapa kotak putih yang mengelilinginya. Oleh sebab itu, agar kotakkotak putih tersebut berkumpul menjadi satu dan tepat berada di wilayah stoma yang benar, perlu adanya proses penggabungan hasil deteksi. Metode penggabungan hasil deteksi yang digunakan pada penelitian ini ialah jarak Euclid (Euclidean distance) yang dapat dilihat pada Gambar 6.

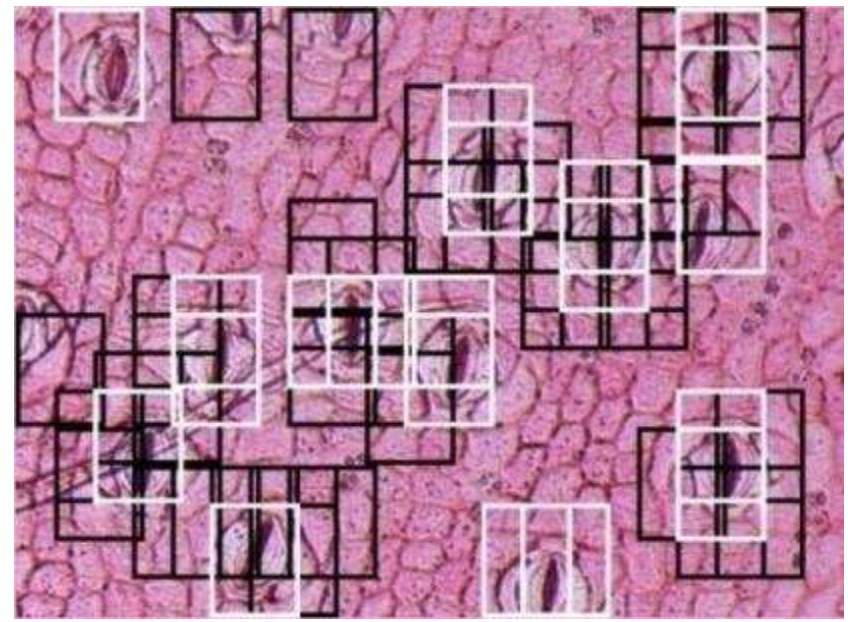

Gambar 5 Hasil deteksi awal

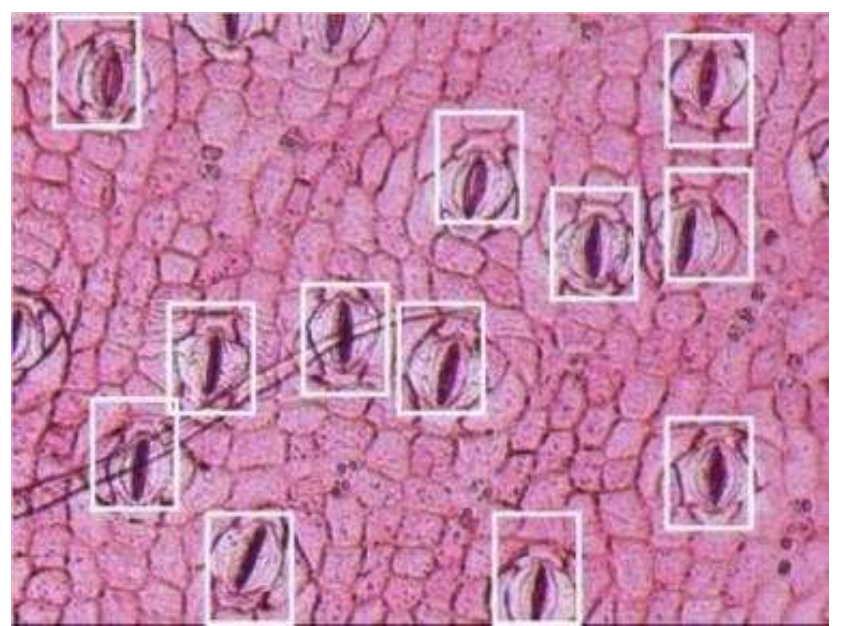

Gambar 6 Hasil penggabungan daerah deteksi 


\section{Analisis Hasil Histogram}

Terdapat lima jaringan terbaik yang dihasilkan histogram berdasarkan jumlah bin yang digunakan pada penelitian ini. Nilai recall, precison, dan $f_{1 \_}$measure yang dihasilkan histogram untuk ketiga jenis spesies dapat dilihat pada Tabel 2.

Tabel 2 Nilai recall, precison, dan $f_{l \_}$measure gabungan dari ketiga jenis spesies yang dihasilkan dari metode histogram

\begin{tabular}{clll}
\hline Jumlah bin & Recall & Precicion & $F_{\text {l_measure }}$ \\
\hline 10 & 0.5840 & 0.8111 & 0.6791 \\
20 & 0.6080 & 0.8261 & 0.7005 \\
30 & 0.6320 & 0.6991 & 0.6639 \\
40 & 0.5360 & 0.7204 & 0.6147 \\
50 & 0.5120 & 0.6667 & 0.5792
\end{tabular}

Agar perbandingan nilai-nilai $f_{1 \_}$measure gabungan dari ketiga jenis spesies terlihat lebih jelas, maka nilai-nilai tersebut akan disajikan kedalam bentuk grafik. Grafik nilai $f_{1 \_}$measure gabungan berdasarkan jumlah bin yang digunakan dapat dilihat pada Gambar 7 .

Berdasarkan grafik pada Gambar 7, dapat dilihat bahwa jumlah bin terbaik untuk mendeteksi kemunculan stoma pada citra penampang daun Freycinetia adalah 20 bin dengan nilai $f_{1 \_}$measure yang dihasilkan adalah 0.7005 . Hal ini terjadi karena 20 bin adalah jumlah titik ekstraksi terbaik yang mampu merepresentasikan karakteristik yang berbeda bagi ketig kelas yang ada (stoma, sebagian stoma, dan bukan stoma).

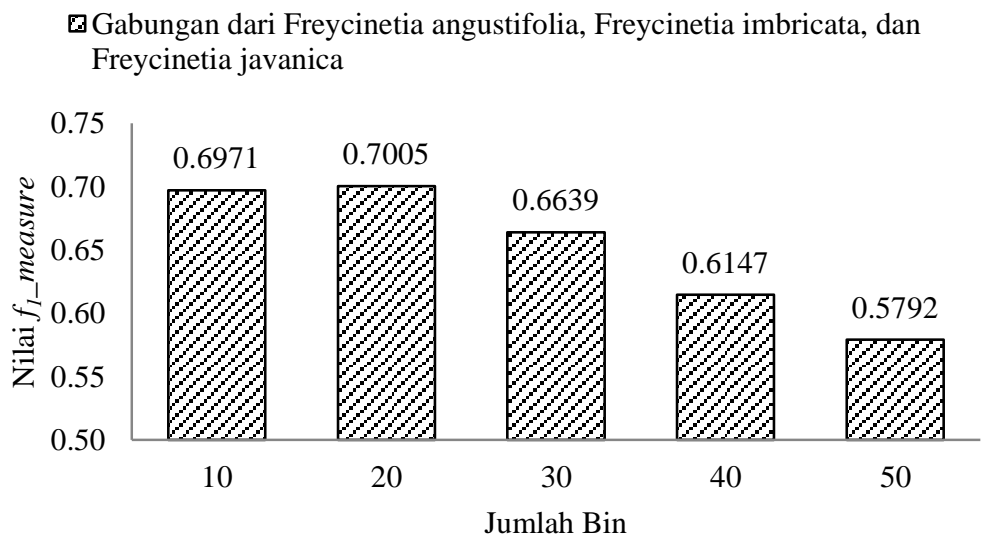

Gambar 7 Nilai $f_{1 \_}$measure gabungan tiga spesies berdasarkan jumlah bin

\section{Analisis Hasil PCA}

Terdapat tujuh jaringan terbaik yang dihasilkan PCA berdasarkan persentase pembuangan komponen utama dengan nilai recall, precison, dan $f_{1 \_}$measure yang dihasilkan PCA untuk ketiga spesies dapat dilihat pada Tabel 3.

Tabel 3 Nilai recall, precison, $f_{1 \_}$measure gabungan dari ketiga jenis spesies yang dihasilkan PCA berdasarkan persentase pembuangan komponen utama

\begin{tabular}{ccll}
\hline $\begin{array}{l}\text { Komponen utama dibuang } \\
\text { jika memiliki kontribusi }\end{array}$ & Recall & Precision & $F_{1 \_ \text {measure }}$ \\
\hline$<0.04 \%$ & 0.9360 & 0.7312 & 0.8211 \\
$<0.05 \%$ & 0.9360 & 0.8478 & 0.8897 \\
$<0.06 \%$ & 0.9600 & 0.7947 & 0.8696 \\
$<0.07 \%$ & 0.9600 & 0.8633 & 0.9091 \\
$<0.08 \%$ & 0.9280 & 0.7785 & 0.8467 \\
$<0.09 \%$ & 0.9360 & 0.6802 & 0.7879 \\
$<0.10 \%$ & 0.9680 & 0.8067 & 0.8800 \\
\hline
\end{tabular}


Persentase pembuangan komponen utama terbaik untuk mendeteksi kemunculan stoma pada citra penampang daun Freycinetia ialah $0.07 \%$, dengan nilai $f_{1 \_}$measure 0.9091 . Namun, dapat dilihat juga bahwa rentang nilai $f_{1 \_}$measure yang dihasilkan tidak terlalu jauh. Selisih antara nilai $f_{1 \_}$measure terbesar dengan nilai $f_{1 \_}$measure terkecil hanya 0.1212 . Hal ini terjadi karena perbedaan nilai persentase pembuangan komponen utama yang digunakan sangat kecil (hanya berbeda $0.01 \%$ di antara nilai persentase digunakan) sehingga jumlah informasi yang dihasilkan hampir sama.

\section{SIMPULAN}

Pada penelitian ini, telah diuji dua metode ekstraksi fitur untuk deteksi kemunculan stoma pada citra mikroskopis penampang daun Freycinetia, yaitu: metode histogram dan PCA. Nilai $f 1 \_m e a s u r e$ terbaik yang mampu dicapai oleh metode ekstraksi ciri Histogram adalah 0.7005, sedangkan metode PCA 0.9091. Secara umum dapat disimpulkan bahwa metode PCA menghasilkan akurasi yang lebih baik dibanding metode histogram, dan mampu memberikan unjuk kerja yang memuaskan sehingga dapat dikembangkan untuk penelitian-penelitian selanjutnya, ataupun untuk digabungkan dengan metode pengenalan spesies Freycinetia yang telah ada sebelumnya, seperti pada Qur'ania (2012).

\section{DAFTAR PUSTAKA}

Gonzalez RC, Woods RE. 2008. Digital Image Processing. Ed ke-3. New Jersey (US): Prentice Hall.

Jolliffe IT. 2002. Principle Component Analysis. Ed ke-2. New York (US): Springer-Verlag. Manning CD, Raghavan P, Schutze D. 2008. Introduction to Information Retrieval. Cambridge (UK): Cambridge University Pr.

Pasaribu N. 2010. Freycinetia (Pandanaceae) of Sumatera [disertasi]. Bogor (ID): Institut Pertanian Bogor.

Qur'ania A. 2012. Klasifikasi Freycinetia berbasis citra anatomi stomata menggunakan kNearest Neighboor dan Jaringan Saraf Tiruan [tesis]. Bogor(ID): Institut Pertanian Bogor.

Sanyal P, Bhattacharya U, Bandyopadhyay SK. 2008. Analysis of SEM images of stomata of different tomato cultivars based on morphological features. Di dalam: Second Asia International Conference on Modelling \& Simulation; 2008 Mei 13-15; Kuala Lumpur, Malaysia. New York (US): IEEE. hlm 890-894.

Willmer CM. 1983. Stoma. New York (US): Longman. 